\title{
Klippel-Trenaunay Syndrome:A Rare Cause of NonHealing Ulcer
}

\author{
${ }^{1}$ Dr Jaswant Mahawer,${ }^{2}$ Dr Avinash Bothra, ${ }^{3}$ Dr Aarti Gupta, ${ }^{4}$ Dr Kirti \\ Department of Pediatrics, SBKSMIRC, Dhiraj Hospital, Pipariya, Gujarat \\ Consultant Resident
}

\section{Introduction}

Klippel-Trenaunay syndrome (KTS) is a rare congenital malformation characterized by triad of varicose veins, cutaneous capillary malformation, and hypertrophy of bone and soft tissue. (1) The port wine stain is a flat, red or purple mark on the skin that is often the only noticeable symptom of Klippel-Trenaunay syndrome at birth. It may be associated with life-threatening complications such as high-output cardiac failure, consumptive coagulopathy, and internal hemorrhages.

\section{Case Report}

A 13 year old female child presented with complaints of multiple ulcers over the left foot since 1 year. Ulcers were non-healing, $3 \times 2 \mathrm{~cm}$ in size with well defined margins and pinkish granulation tissue. The surrounding skin was discolored, swollen and was edematous. It felt warm on touch. No discharge or bleeding was present. Edema was present around the lesion extending up to knee, pitting type, associated with swelling of left limb, pain and swelling was aggravated while walking and relieved on taking rest. It was associated with restriction of left ankle movement. Peripheral Sensations to touch, pain and temperature was intact. Varicose veins were present below knees.

\section{General examination}

patient was averagely built and nourished. Conscious and well oriented, Vitals were stable; all peripheral pulses were palpable, Blood pressure was within the normal range, mild pallor was present.

There was no icterus, cyanosis, clubbing or lymphadenopathy.

\section{Local examination}

Unilateral well defined large Port wine stain was present over left side of lower abdomen involving lower back, buttocks and thigh up to left knee. The surface was smooth and no bleeding points. Margins were irregular. (Figure 1)

Varicose veins were present below knees. (Figure 2)
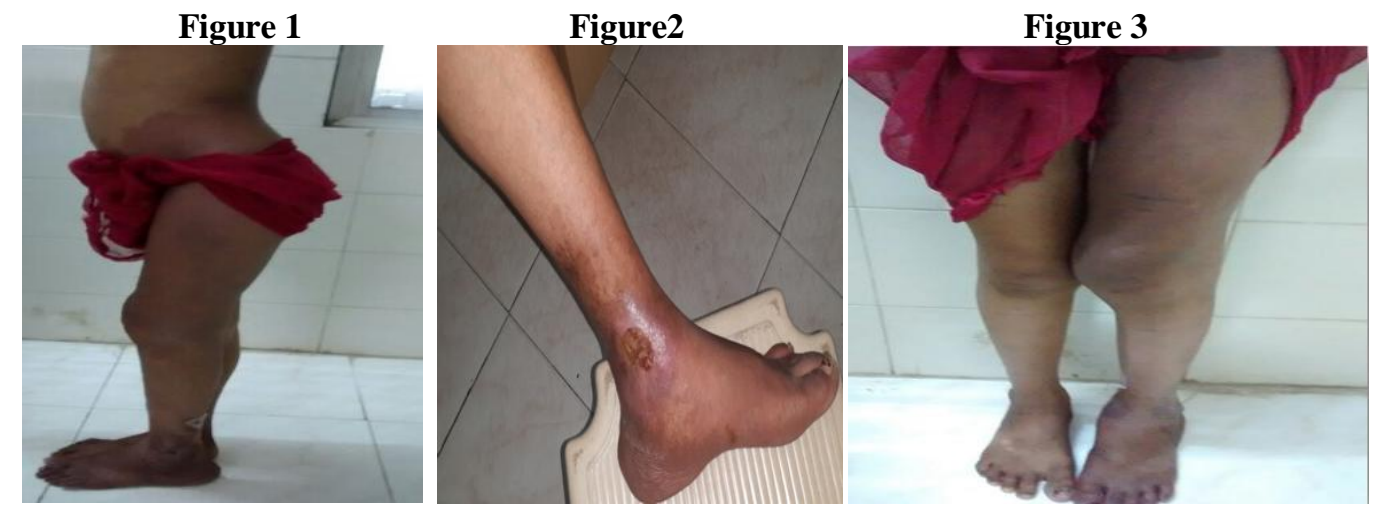

Girl had a limping gait due to limb length disparency. Left lower Limb hypertrophy was present. True limb shortening was present $-3 \mathrm{~cm}$. (figure 3 ) Rest of the systemic examination was normal.

\section{Investigation}

Complete hemogram: shows Hb: 10.4 gm\%, TLC: 7400 per millimeter cube,

DC: Neutrophils-65 /Lymphocytes:27/Monocytes:4/Eosinophils:4, ESR: 40 mm.

- Urine routine examination is normal.

- Stool for occult blood is negative 
- X-ray was normal and showed no underlying abnormality.

- Doppler: Long saphenous vein and short saphenous vein appeared dilated and tortuous along its course. Multiple dilated tortuous perforators were noted in the lower leg- 2 on medial side and 2 on posterior side.

\section{Management}

1. Supportive care: compression bandage for varicosities, surgical treatment in selected cases. ${ }^{(2)}$

2. Percutaneous sclerotheraphy guided by color echo doppler sonography for venous abnormalities.

3. Leg-length differences may be treated with orthotic devices to prevent development of spine deformities.

4. Corrective bone surgery may be required in selected cases if there is significant limb length discrepancy. ${ }^{(3)}$

\section{Discussion}

Klippel-Trenaunay syndrome is characterized by a combined type of vascular malformation of the skin, abnormalities of the venous system and lymphatic system, and limb enlargement due to hypertrophy of soft tissue and bone and limb asymmetry. ${ }^{(4)}$

In 1900 Maurice klipple and Paul Trenaunay had described $\mathrm{KTS}^{(5)}$. It is also named as Angioosteohypertrophy Syndrome, Osteo-hypertrophy nevus flammeus, congenital dysplastic angiectasis and elephantiasis congenital angiomatosa. It is a non-heritable syndrome.

The syndrome usually occurs sporadically with rare cases having a familial predilection ${ }^{(6,7)}$. Both sexes are equally affected. The cause of the syndrome is unknown but several theories exist. One such theory is the presence of a mesodermal defect during embryogenesis causing the persistence of microscopic arteriovenous (AV) communications. ${ }^{(8)}$ Yet another theory postulates that intra-uterine damage to the sympathetic ganglia or inferiomedial lateral tract leads to microscopic AV communications. ${ }^{(9)}$

The clinical features are usually that of a haemangioma that appears first and at birth. The same may be present on any part of the body although the face and cervical region are most commonly affected. The midline is not crossed and the haemangioma does not involute but gets progressively larger with the growth of the child.

The anomaly is present at birth and usually involves a lower limb, may involve trunk and portions of face. One limb is affected in $75 \%$ of cases. Enlargement of soft tissues is gradual and may involve the entire extremity or a portion of it or selected digits. Thick walled venous varicosities develop on ipsilateral side as the child begins to ambulate.

The hemihypertrophy is due to hyperplasia of both bone and soft tissue with or without vascular malformations, both superficial (port-wine stains are most common, nevus flammeus) and deep (cavernous) hemangiomas can be present. If there is an associated AVM then it is called Klippel Trenaunay-Weber syndrome. ${ }^{(10)}$

Diagnosis is essentially clinical. Work-up of the lesion may involve noninvasive imaging: Doppler ultrasound, standard radiography, or magnetic resonance imaging (MRI). The presence of arteriovenous malformations is sought by clinical examination or ultrasound: they rule out a diagnosis of KTS. Management is multidisciplinary and involves especially venous control and orthopedic management of unequal limb lengths. ${ }^{(11)}$

May be associated with limb swelling, pain, gangrene, venous ulcers, developmental defects include polydactyly, oligodactyly, macrocephaly, blue nevi, pulmonary vein varicosities, cerebral aneurysm, gastrointestinal hemorrhage, pulmonary embolism, incompetent valves in veins, and visceral venous malformations .

The syndrome is usually benign and management supportive unless complications occur. Complications may include bleeding, cellulitis, venous thrombosis, pulmonary embolism, hand and foot anomalies and lymphoedema.

There is no curative treatment for KTS and management is symptomatic relief and treatment of complications such as bleeding, pain and length discrepancies. Pulsed laser dye therapy is used for port wine stains. Varicosities causing venous insufficiency are treated with compression stockings and surgical treatment may be used for superficial symptomatic varicosities. Complications such as cellulitis, deep vein thrombosis and superficial thrombo phlebitis are managed medically .

Surgical management may be necessary in some cases to correct uneven growth, debulk soft tissues and removal of excess veins or haemangioma. Possible procedures include osteotomy, epiphysiodesis and epiphyseal stapling . Followup monitoring should be done at least annually and intervention given if indicated.

\section{References}

[1]. Phillips GN, Gordon DH, Martin EC et-al. The Klippel-Trenaunay syndrome: clinical and radiological aspects. Radiology. 1978;128 (2): 429-34.doi:10.1148/128.2.429 - Pubmed citation

[2]. Gloviczki P, Driscoll DJ. Klippel-Trenaunay syndrome: current management. Phlebology. 2007;22(6):291-8. Review. PubMed citation 
[3]. Jacob AG, Driscoll DJ, Shaughnessy WJ, Stanson AW, Clay RP, Gloviczki P. Klippel-Trénaunay syndrome: spectrum and management. Mayo Clin Proc. 1998s Jan;73(1):28-36. PubMed citation

[4]. Berry SA ${ }^{1}$, Peterson C, Mize W, Bloom K, Zachary C, Blasco P, Hunter D. Klippel-Trenaunay syndrome. Am J Med Genet. 1998 Oct 2;79(4):319-26.

[5]. Klippel M, Trénaunay P. De naevus variqueux ostéohypertrophique. Arch Gen Méd (Paris), 1900; $185: 641$-72

[6]. Lindenauer SM. The Klippel-Trenauny syndrome: varicosity, hypertrophy and haemangioma with no arteriovenous fistula. Ann Surg1965; 162: 303-14.

[7]. Resnick D, Niwayama G, eds. Diagnosis of bone and joint disorders. $2^{\text {nd }}$ ed. Philadelphia: WB Saunders; 1984: 541.

[8]. Baskerville PA, Ackroyd JS, Browse NL. The etiology of the Klippel-Trenaunay syndrome. Ann Surg 1985; 202:624-7.

[9]. Bliznak J, Staple TW. Radiology of angiodysplasias of the limb. Radiology 1974; 110: 35-44.

[10]. IWeber FP. Angioma formation in connection with hypertrophy of limbs and hemihypertrophy. Brit J Derm 1907; $19: 231-5$.

[11]. ISamimi M ${ }^{1}$, Lorette G. [Klippel-Trenaunay syndrome]. Presse Med. 2010 Apr;39(4):487-94. doi: 10.1016/j.lpm.2009.10.016. Epub $2010 \mathrm{Feb} 26$. 